\title{
Zinc and vitamin $\mathrm{C}$ deficiencies associate with poor pulmonary function in children with persistent asthma
}

\author{
Siriporn Siripornpanich, ${ }^{1}$ Nalinee Chongviriyaphan, ${ }^{2}$ Wiparat Manuyakorn, ${ }^{3}$ Ponpan Matangkasombut ${ }^{4,5}$
}

\begin{abstract}
Background: One of the pathophysiologic mechanisms involved in asthma is the increase in oxidative stress. Zinc (Zn), vitamin $\mathrm{C}(\mathrm{VC})$, and vitamin $\mathrm{E}$ (VE) have antioxidant functions. However, the status of oxidative stress, Zn, VC, and $\mathrm{VE}$ in Thai asthmatic children have not been reported.
\end{abstract}

Objective: We aimed to evaluate the status of oxidative stress, Zn, VC, VE, pulmonary function tests, and airway inflammation in Thai asthmatic children with persistent asthma.

Methods: In this cross-sectional study, the data was collected from asthmatic children aged 7-17 years. The plasma $\mathrm{PGF}_{2 \alpha}$ concentration as a marker of oxidative stress was measured using an ELISA kit. Plasma Zn concentration was measured through atomic absorption spectrophotometry. Plasma VC and VE concentrations were determined using HPLC. Pulmonary function tests were evaluated as forced expiratory volume in first second $\left(\mathrm{FEV}_{1}\right)$ and forced vital capacity (FVC), using a spirometer. The status of airway inflammation was determined by measuring fractional exhaled nitric oxide.

Results: There were 76 asthmatic children in this study. Seventy-two participants had high oxidative stress. All participants had Zn deficiency. Nearly $40 \%$ of participants had VC deficiency. VC deficiency was associated with severe asthma and airway obstruction. Plasma $\mathrm{Zn}$ concentrations were positively correlated with $\mathrm{FEV}_{1}(\mathrm{r}=0.27)$ and $\mathrm{FEV} / \mathrm{FVC}$ ratio $(r=0.65)$.

Conclusion: Deficiency of $\mathrm{Zn}$ and/or VC was related to severe asthma and decreased pulmonary function. Nutrition assessment and management should be considered to alleviate asthma burden.

Key words: asthmatic children, pulmonary function tests, zinc, vitamin C, vitamin E

\section{Citation:}

Siripornpanich, S., Chongviriyaphan, N., Manuyakorn, W., Matangkasombut, P. (2022). Zinc and vitamin C deficiencies associate with poor pulmonary function in children with persistent asthma. Asian Pac J Allergy Immunol, 40(2), 103-110. https://doi. org/10.12932/ap-100620-0878

\section{Affiliations:}

${ }^{1}$ Graduate student in Doctor of Philosophy Program in Nutrition, Faculty of Medicine Ramathibodi Hospital and Institute of Nutrition, Mahidol University, Thailand

${ }^{2}$ Division of Nutrition, Department of Pediatrics, Faculty of Medicine Ramathibodi Hospital, Mahidol University, Bangkok, Thailand Division of Pediatrics Allergy and Immunology,

Department of Pediatrics, Faculty of Medicine Ramathibodi Hospital, Mahidol University, Bangkok, Thailand

${ }^{4}$ Department of Microbiology, Faculty of Science, Mahidol University, Bangkok, Thailand

5 Systems Biology of Diseases Research Unit, Faculty of Science, Mahidol University, Bangkok, Thailand

\section{Corresponding author:}

Nalinee Chongviriyaphan

Division of Nutrition, Department of Pediatrics,

Faculty of Medicine Ramathibodi Hospital, Mahidol University, 270 Rama 6 Road, Toong Phayathai subdistrict, Ratchathewi district, Bangkok 10400, Thailand

E-mail: nalinee.cho@mahidol.edu

\section{Introduction}

Asthma is one of the most common chronic inflammatory disorders of the airway, impacting approximately 5-20\% of children worldwide. ${ }^{1}$ Asthmatic children are more likely to miss classes and have limitation in physical activity or exercise.

The major characteristics of asthma are chronic airway inflammation and airway hyperresponsiveness (AHR), leading to recurrent airflow obstruction. Presently, it has been documented that oxidative stress is the cause, aggravating factor, and the consequence of airway inflammation and AHR., 
Disequilibrium, via either an increase in oxidative stress or compromised antioxidant resources, promote the symptoms of asthma.

A compound, 8-iso-prostaglandin $\mathrm{F}_{2 \alpha}\left(\mathrm{PGF}_{2 \alpha}\right)$, formed by lipid peroxidation of arachidonic acids (AAs) in cell membrane, is an oxidative stress product. PGF $_{2 \alpha}$ induces inflammatory cytokine production and recruits inflammatory cells in the airway. ${ }^{4}$ Such inflammation causes swelling, mucus hypersecretion, and smooth muscle contraction of the airway, resulting in airway narrowing. ${ }^{5} \mathrm{PGF}_{2 \alpha}$ is one of the markers to determine oxidative stress status in patients with asthma.

Non-enzymatic antioxidants, including zinc ( $\mathrm{Zn})$, vitamin $\mathrm{C}$ (VC), and vitamin E (VE), provide protection against oxidative stress. VC provides intra- and extra-cellular aqueous antioxidant capacity. VE protects polyunsaturated fatty acids in cell membrane from lipid peroxidation, therefore preserving cell membrane functions. Zn exerts an antioxidant effect by reducing hydroxyl radical formation from hydrogen peroxide through the antagonism of redox-active transition metals such as iron and copper. In addition, $\mathrm{Zn}$ acts as a cofactor of superoxide dismutase, an antioxidative enzyme. Accordingly, deficiencies of these antioxidants could lead to pulmonary damage that worsens asthma symptoms.

Several observational studies demonstrated that asthmatic patients had low levels of serum $\mathrm{Zn}, \mathrm{VC}$, and $\mathrm{VE}$ than the healthy population. ${ }^{6,7}$ However, some research did not find any different in these nutrients between asthmatic patients and healthy population. ${ }^{8}$ This discrepancy may be due to different factors, such as age, ethnicity, eating patterns, as well as exposure to environmental pollutants, in patients. At present, the information on the association among levels of these nutrients, level of asthma severity, degree of asthma control, and airway inflammation in human are sparse. Moreover, there is no study reported on oxidative stress and antioxidant status in Thai children with persistent asthma.

Thus, this study was conducted to determine the status of oxidative stress, antioxidants, and airway inflammation in Thai children with persistent asthma and to determine the association among oxidative stress, antioxidant status, airway inflammation, asthma severity, asthma control levels, and pulmonary function tests of the studied population.

\section{Methods}

\section{Study design and subjects}

This was a cross-sectional study. We enrolled children, aged 7-17 years, who were diagnosed asthma, according to the Global Strategy for Asthma Management and Prevention updated in the 2015, the NHLBI/WHO workshop report; Global Initiative for Asthma (GINA), ${ }^{9}$ for at least 6 months. The recruitment was performed at the allergy clinic, Department of Pediatrics, Faculty of Medicine Ramathibodi Hospital, Mahidol University between October 2015 and May 2016.

Asthmatic children who were eligible to participate in this study were those with persistent asthma per GINA guideline. ${ }^{9}$ To ensure the results were not affected by the change in asthma control and treatment regimen, all subjects recruited were clinically stable and anti-asthmatic drugs including inhaled corticosteroid (ICS) dose remain unchanged for at least 4 weeks prior to data collection. The exclusion criteria include the change of asthma severity and levels of asthma control as well as anti-asthmatic drugs during data collection processes, having pulmonary or chronic systemic diseases other than asthma and allergic rhinitis, immunodeficiency, a history of premature birth, an infection or major surgery or had received anesthesia in the past 4 weeks, taking drugs that were not for treatment of asthma but could affect the symptoms of asthma such as aspirin and $\beta$-blockers in the past 4 weeks, taking supplementation of either $\mathrm{Zn}, \mathrm{VC}$, or $\mathrm{VE}$ in the past 4 weeks, taking anti-inflammatory drugs in the past 4 weeks, smoking, pregnancy, and participating in other clinical trials.

All participants provided informed consent, and the study was conducted in accordance with the Declaration of Helsinki and approved by Human Research Ethics Committee, Faculty of Medicine Ramathibodi Hospital, Mahidol University (ID 08-57-11).

\section{Data collection}

Demographic characteristics were reported by parents of participants using questionnaires. Medical data such as severity of asthma, levels of asthma control, and medications were collected from medical records. Height was measured using a standard stadiometer and weight was measured using a calibrated digital scale. Dietary intakes of $\mathrm{Zn}, \mathrm{VC}$, and VE were collected using semi-quantitative food frequency questionnaires (FFQ), providing the frequency and the average quantity of each food item consumed during 4 weeks before the visit. Dietary intakes of VC were calculated using the INMUCAL-nutrients software from the Institute of Nutrition, Mahidol University. Since the data of the amount of dietary $\mathrm{Zn}$ and VE were insufficient in the INMUCAL-nutrients software, the dietary intakes of $\mathrm{Zn}$ and VE were calculated using the United States Department of Agriculture National Nutrient Database for Standard Reference Release 25.

\section{Pulmonary function tests}

Spirometry was performed in all participants by using a multi-functional spirometer HI-801 (CHEST M.I., INC.; Tokyo, Japan). The data of pulmonary function tests included forced vital capacity (FVC) and forced expiratory in first second $\left(\mathrm{FEV}_{1}\right)$. The measurement and interpretation of pulmonary function tests were performed according to the criteria of the American Thoracic Society (ATS) and the European Respiratory Society (ERS) recommendations. ${ }^{10}$ The cut-off value for abnormal $\mathrm{FEV}_{1}$ was $\% \mathrm{FEV}_{1}$ equal to or less than $80 \%$ of the predicted value and the cut-off value for airway obstruction was $\mathrm{FEV}_{1} / \mathrm{FVC}$ equal to or less than $90 \%$.

\section{Fractional exhaled nitric oxide (FENO)}

Fractional exhaled nitric oxide was measured by a trained technician using a CLD 88sp FENO analyzer (ECO MEDICS; Duernten, Switzerland). The measurement and interpretation of FENO measurement were done according to the ATS and the ERS recommendations; that is taking a single breath exhalation-online method. ${ }^{11}$ The cut-off values for low, intermediate, and high FENO categories are < 25, 25-50, and $>50 \mathrm{ppb}$, respectively (for children aged less than 12 years, the cut-off values are $<20,20-35$, and $>35 \mathrm{ppb}$, respectively). 
The intermediate and high FENO categories were interpreted as eosinophilic airway inflammation.

\section{Blood collection and biochemical analysis}

Blood was drawn from an antecubital vein by a registered nurse. Five $\mathrm{mL}$ of blood were collected in an EDTA-containing tube, centrifuged at 3,000 rpm for 10 minutes; then, stored at $-80^{\circ} \mathrm{C}$ until analysis of plasma $\mathrm{Zn}, \mathrm{VE}$, and $\mathrm{PGF}_{2 a}$.

Two $\mathrm{mL}$ of blood were collected in a heparin-containing tube, centrifuged at 3,000 rpm for 10 minutes; then the supernatant was mixed with $10 \%$ metaphosphoric acid. The mixture was centrifuged, filtered, separated into aliquots in microtubes wrapped with aluminium foil for light protection, and stored at $-80^{\circ} \mathrm{C}$ until plasma $\mathrm{VC}$ analysis.

Plasma $\mathrm{Zn}$ concentrations were measured through atomic absorption spectrophotometry by using GBC Avanta S AAS (GBC Scientific Equipment Pty Ltd.; Dandenong, Australia). Plasma VC and VE concentrations were measured through high performance liquid chromatography (HPLC) using the Waters 2475 Multi $\lambda$ Fluorescence Detector (Waters Corpora-

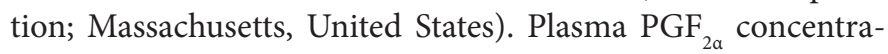
tions were measured using the OxiSelect 8-iso-prostaglandin $\mathrm{F}_{2 \alpha}$ ELISA kit (STA-337: 96 assays per kit) (Cell Biolabs; California, United States).

\section{Statistical analysis}

A sample size of 69 subjects was estimated, considering a case-controlled prospective study by Al-Abdulla et al. in $2010,{ }^{12}$ accepting type I error of 0.05 , a power of $95 \%$, and an effect size 1.1094 in the association between asthma severity and oxidative stress markers present in peripheral blood.

The Kolmogorov-Smirnov test was used for normality of the distribution. Normal distributed data are expressed as the mean and standard deviation. Non-normal distributed data are expressed as the median and range. Levene's statistic test was used for homogeneity of variances. Differences in normal distributed continuous variables between categories were tested using Student's $t$-test or one-way ANOVA with Scheffe's method as a post hoc analysis. Differences in categorical variables were tested using the $\chi^{2}$-test. The relationship between two normal distributed continuous variables was tested using the Pearson correlation coefficient. Statistical analysis was performed using the SPSS program version 19. A p-value less than 0.05 was considered statistically significant.

\section{Results}

There were 76 participants enrolled in this study. Complete data were available for 71 participants; 4 participants had symptoms of acute upper respiratory tract infection so they could not undergo the FENO procedure and one participant could not be assessed for plasma VE concentration due to insufficient blood volume.

The mean age of participants was 11.76 years. The numbers of participants among mild, moderate, and severe asthma were similar. Most of participants had completely controlled asthma. One fifth of participants (17.11\%) had abnormal $\mathrm{FEV}_{1}$ values. The majority of participants (67.11\%) had airway obstruction. A few participants (12.5\%) had eosinophilic airway inflammation. The clinical characteristics of participants are shown in Table 1.

Table 1. Clinical characteristics of asthmatic participants

\begin{tabular}{|c|c|}
\hline Characteristics & Number (\%) \\
\hline \multicolumn{2}{|l|}{ Gender } \\
\hline - Men & $53(69.74)$ \\
\hline - Women & $23(30.26)$ \\
\hline Height for age (\% standard) & $101.23 \pm 4.21^{*}$ \\
\hline Weight for age (\% standard) & $123.99 \pm 29.12^{*}$ \\
\hline Weight for height (\% standard) & $117.88 \pm 21.45^{*}$ \\
\hline Having tobacco smoke exposure & $24(31.58)$ \\
\hline Having allergic rhinitis & $71(93.42)$ \\
\hline \multicolumn{2}{|l|}{ Type of allergic rhinitis $(\mathrm{n}=71)$} \\
\hline - Mild intermittent & $50(70.42)$ \\
\hline - Mild persistent & $16(22.54)$ \\
\hline - Moderate to severe persistent & $5(7.04)$ \\
\hline \multicolumn{2}{|l|}{ Asthma severity $^{\dagger}$} \\
\hline - Mild & $27(35.52)$ \\
\hline - Moderate & $29(38.16)$ \\
\hline - Severe & $20(26.32)$ \\
\hline \multicolumn{2}{|l|}{ Asthma control $^{*}$} \\
\hline - Completely controlled & $60(78.95)$ \\
\hline - Incompletely controlled & $16(21.05)$ \\
\hline \multicolumn{2}{|l|}{ Pulmonary function tests } \\
\hline - $\mathrm{FEV}_{1}(\%$ predicted $)$ & $95.96 \pm 18.55^{*}$ \\
\hline - $\mathrm{FEV}_{1} / \mathrm{FVC}$ ratio (\%) & $86.93 \pm 6.02^{*}$ \\
\hline Having eosinophilic airway inflammation $(n=72)$ & $9(12.5)$ \\
\hline
\end{tabular}

${ }^{*}$ Data is reported in mean \pm SD.

${ }^{\dagger}$ Asthma severity was categorized according to the GINA, updated 2015'; mild asthma group comprised patients who were taking low dose of inhaled corticosteroid (ICS). Moderate asthma group comprised patients taking medium or high dose of ICS or using low dose of ICS plus either long-acting inhaled $\beta_{2}$-agonist (LABA) or leukotriene receptor antagonist (LTRA). Severe asthma group comprised patients taking medium or high dose of ICS plus either LABA or LTRA or taking ICS plus LABA plus LTRA.

${ }^{\ddagger}$ Asthma control was categorized according to the GINA, updated 2015\%; asthmatic patients had none of the following in the past 4 weeks: 1) daytime symptoms $>2$ (week, 2) any night waking due to asthma, 3) using reliever (short-acting inhaled $\beta_{2}$-agonist) $>2 /$ week, 4 ) any activity limitation due to asthma were classified as completely controlled asthma. Asthmatic patients having at least one of those criteria were classified as incompletely controlled asthma.

The medians of dietary $\mathrm{Zn}, \mathrm{VC}$, and VE intakes were 48 (range 3.00-203.10), 3.68 (range 1.30-11.68), and 5.77 (range 4.08-10.53) $\mathrm{mg} /$ day, respectively. The median intakes of $\mathrm{Zn}$ and VC was within reference ranges (4-8 and 40-90 mg/ day, respectively) equivalent to 105.44 and $96.23 \%$ of recommended intakes of $\mathrm{Zn}$ and $\mathrm{VC}$, according to Thai dietary 
reference intakes (2003), respectively. However, the dietary VE intake was low (31.85\% of that recommended).

The mean plasma concentration of $\mathrm{PGF}_{2 \alpha}$ was $134.48 \mathrm{pg} /$ $\mathrm{mL}$ (normal $40-100 \mathrm{pg} / \mathrm{mL}$ ). Almost $96 \%$ of participants had high oxidative stress. The mean plasma concentrations of $\mathrm{Zn}$, $\mathrm{VC}$, and VE were $54.13 \mu \mathrm{g} / \mathrm{dL}, 3.07 \mu \mathrm{g} / \mathrm{mL}$, and 1,320.73 $\mu \mathrm{g} /$ $\mathrm{dL}$, respectively; whereas the normal values of plasma $\mathrm{Zn}$, $\mathrm{VC}$, and VE are $80-120 \mu \mathrm{g} / \mathrm{dL}, 2-20 \mu \mathrm{g} / \mathrm{mL}$, and 600-1,400 $\mu \mathrm{g} /$ $\mathrm{dL}$, respectively. ${ }^{13}$ All participants had $\mathrm{Zn}$ deficiency, however there was no statistically significant correlation between plasma concentrations and dietary intake of $\mathrm{Zn}$. Around 40\% (30 children) had VC deficiency with respect to the above criteria. All participants had normal plasma VE concentrations. Plasma concentrations of $\mathrm{PGF}_{2 a}, \mathrm{Zn}, \mathrm{VC}$, and VE did not significantly differ among participants according to age, gender, having allergic rhinitis, and exposure to tobacco smoke.

The mean plasma concentration of $\mathrm{VC}$ in participants with severe asthma was significantly lower than that of those with moderate and mild asthma. Plasma concentrations of $\mathrm{PGF}_{2 a}, \mathrm{Zn}, \mathrm{VC}$, and VE did not differ among asthmatic participants with completely and incompletely controlled asthma. The mean plasma concentration of $\mathrm{PGF}_{2 \alpha}$ in participants with severe asthma was slightly higher than that in those with moderate and mild asthma; however, it did not reach a significant level. Plasma concentrations of $\mathrm{PGF}_{2 a}, \mathrm{Zn}, \mathrm{VC}$, and VE in participants according to asthma severity are shown in Table 2.

A significantly positive correlation was noted between the plasma $\mathrm{Zn}$ concentrations and $\mathrm{FEV}_{1}$ values as well as the $\mathrm{FEV}_{1} / \mathrm{FVC}$ ratio (Figure $\mathbf{1 A}$ and $\mathbf{B}$ ). A weak positive correlation was observed between the plasma $\mathrm{VC}$ concentrations and the $\mathrm{FEV}_{1} / \mathrm{FVC}$ ratio (Figure 2). Plasma $\mathrm{PGF}_{2 \alpha}$ and VE concentrations were not significantly correlated with pulmonary function parameters.

Regarding the VC status, we classified participants into two groups as follows: the normal VC status group and the VC deficiency group. There were significantly more participants with severe asthma in the VC deficiency group than in the normal VC group. In addition, eosinophilic airway inflammation was detected in the VC deficiency group more than that in the normal VC group with a statistical significance. Both groups had airway obstruction; those in the VC deficiency group had significantly more airway obstruction than the other group (Figure 3). Medical data of asthmatic children according to the VC status are shown in Table 3.

Table 2. Concentrations of plasma prostaglandin $\mathrm{F}_{2 \alpha}\left(\mathrm{PGF}_{2 \alpha}\right)$, zinc $(\mathrm{Zn})$, vitamin $\mathrm{C}(\mathrm{VC})$, and vitamin $\mathrm{E}$ (VE) according to severity of asthma

\begin{tabular}{lcccc} 
& \multicolumn{3}{c}{ Asthma severity } & P \\
\cline { 2 - 4 } Plasma concentration & Mild $(\mathbf{n}=\mathbf{2 7})$ & Moderate $(\mathbf{n}=29)$ & Severe $(\mathbf{n}=20)$ & \\
\cline { 2 - 4 } $\mathrm{PGF}_{2 \mathrm{a}}(\mathrm{pg} / \mathrm{mL})$ & $129.16 \pm 14.05$ & $135.18 \pm 26.97$ & $140.66 \pm 16.86$ & 0.06 \\
$\mathrm{Zn}(\mu \mathrm{g} / \mathrm{dL})$ & $53.23 \pm 9.94$ & $54.65 \pm 8.70$ & $54.58 \pm 9.0$ & 0.82 \\
$\mathrm{VC}(\mu \mathrm{g} / \mathrm{mL})$ & $3.39 \pm 2.09^{\mathrm{a}}$ & $3.52 \pm 1.95^{\mathrm{a}}$ & $1.97 \pm 1.91^{\mathrm{b}}$ & 0.004 \\
$\mathrm{VE}(\mu \mathrm{g} / \mathrm{dL})(\mathrm{n}=75)$ & $1,239.36 \pm 203.97$ & $1,431.98 \pm 436.43$ & $1,266.57 \pm 256.66$ & 0.13 \\
\hline
\end{tabular}

* Criteria using the GINA, updated $2015^{9}$

Data is expressed as mean \pm SD.

The differences between groups were analyzed using 1-way ANOVA with Scheffe' method as a post hoc analysis.

In the same row, mean \pm standard deviation followed by the same small letter are not significantly different at the level 0.05 of $p$-value using Scheffe' method.

A

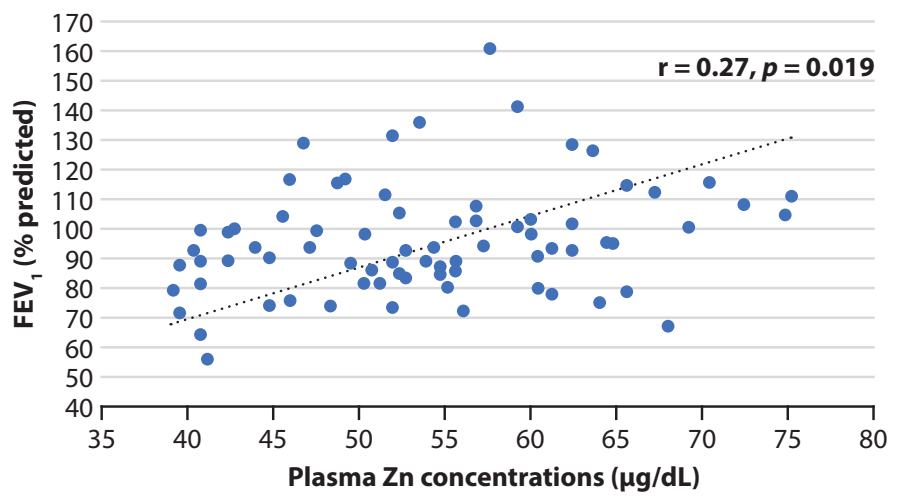

B

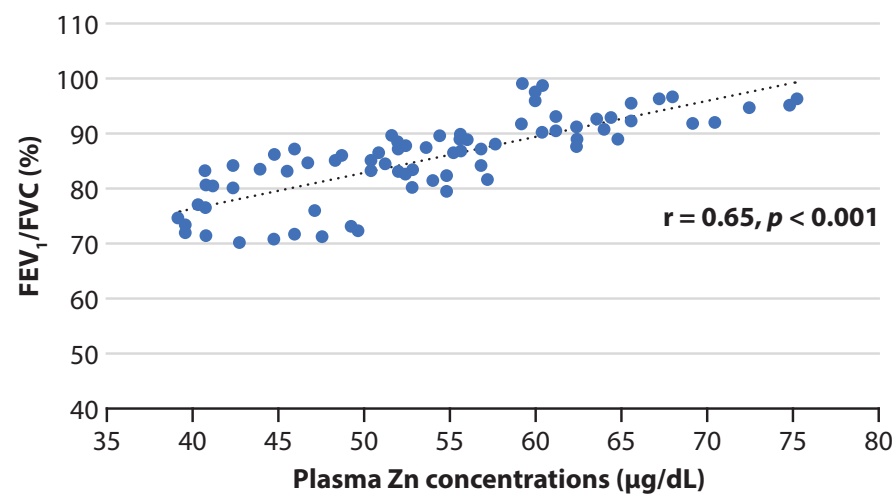

Figure 1. The association between plasma zinc concentrations and forced expiratory volume in the first second (FEV $)$ levels (A) and forced expiratory volume in the first second $\left(\mathrm{FEV}_{1}\right)$ to forced vital capacity $(\mathrm{FVC})$ ratio $\left(\mathrm{FEV}_{1} / \mathrm{FVC}\right.$ ratio) $(\mathrm{B})$

The association between variables was analyzed using Pearson correlation coefficient $\mathrm{Zn}$, zinc 


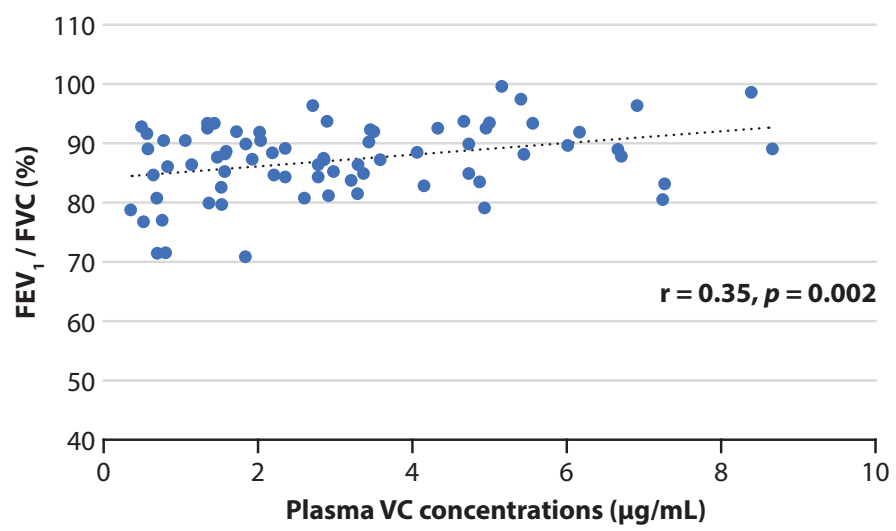

Figure 2. The association between plasma vitamin $\mathrm{C}$ concentrations and forced expiratory volume in the first second $\left(\mathrm{FEV}_{1}\right)$ to forced vital capacity $(\mathrm{FVC})$ ratio $\left(\mathrm{FEV}_{1} / \mathrm{FVC}\right.$ ratio)

The association between variables was analyzed using Pearson correlation coefficient.

VC, vitamin C

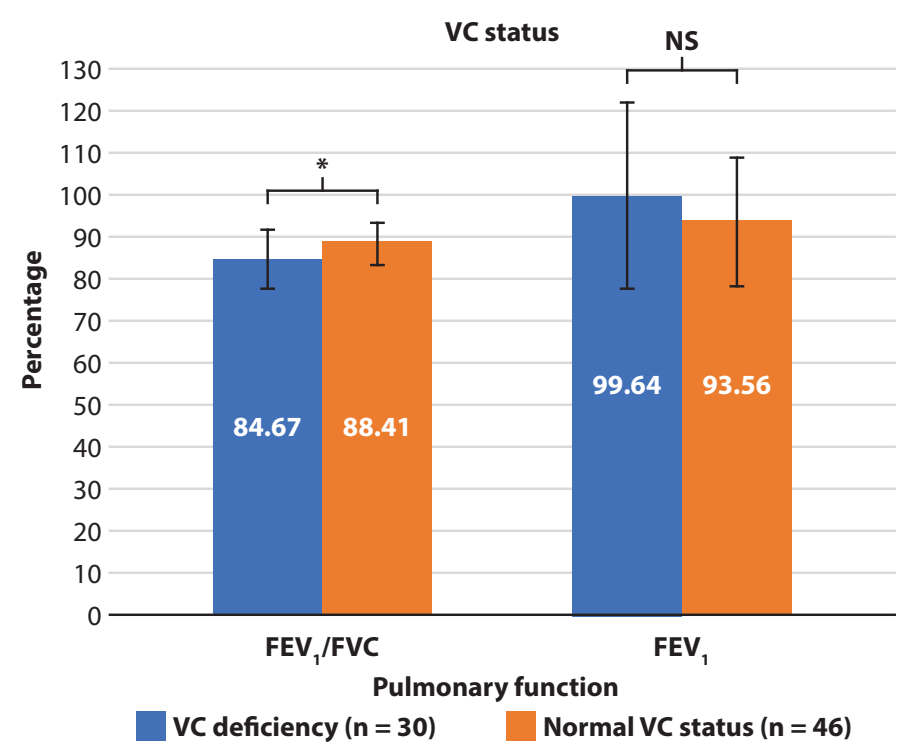

Figure 3. The mean forced expiratory volume in the first second $\left(F_{1}\right)$ to forced vital capacity (FVC) ratio and the mean forced expiratory volume in the first second $\left(\mathrm{FEV}_{1}\right)$ levels according to vitamin $\mathrm{C}$ status

The differences between groups were analyzed using Student's $t$-test. * Significant $(p=0.01)$

NS, not significant; VC, vitamin C

Table 3. Demographic and medical data of asthmatic participants according to vitamin $\mathrm{C}$ status

\begin{tabular}{|c|c|c|c|}
\hline \multirow[b]{2}{*}{ Characteristics } & \multicolumn{2}{|c|}{ VC status [Number (\%)] } & \multirow[b]{2}{*}{$p$-value } \\
\hline & $\begin{array}{c}\text { Normal } \\
\text { (plasma VC } 2-20 \mu \mathrm{g} / \mathrm{mL}) \\
(\mathrm{n}=46)\end{array}$ & $\begin{array}{c}\text { Deficiency } \\
\text { (plasma VC }<2 \mu \mathrm{g} / \mathrm{mL}) \\
(\mathrm{n}=30)\end{array}$ & \\
\hline Age (year) & $11.38 \pm 2.41^{*}$ & $12.35 \pm 2.41^{*}$ & $0.09^{\dagger}$ \\
\hline \multicolumn{4}{|l|}{ Gender } \\
\hline - Men & $31(67.39)$ & $22(73.33)$ & 0.58 \\
\hline - Women & $15(32.61)$ & $8(26.67)$ & \\
\hline \multicolumn{4}{|l|}{ Having smoking exposure } \\
\hline - Yes & $14(30.43)$ & $10(33.33)$ & 0.79 \\
\hline - No & $32(69.57)$ & $20(66.67)$ & \\
\hline \multicolumn{4}{|l|}{ Asthma severity } \\
\hline - Mild & $43.48(20)$ & $23.33(7)$ & \\
\hline - Moderate & $45.65(21)$ & $26.67(8)$ & $<0.001$ \\
\hline - Severe & $10.87(5)$ & $50(15)$ & \\
\hline \multicolumn{4}{|l|}{ Asthma control } \\
\hline - Completely controlled & $84.78(39)$ & $70(21)$ & 0.12 \\
\hline - Incompletely controlled & $15.22(7)$ & $30(9)$ & \\
\hline \multicolumn{4}{|l|}{ Airway inflammation $(\mathrm{n}=72)$} \\
\hline - Yes & $4.65(2)$ & $24.14(7)$ & 0.025 \\
\hline - No & $95.35(41)$ & $75.86(22)$ & \\
\hline Plasma PGF $_{2 a}(p g / m L)$ & $132.10 \pm 20.18^{*}$ & $138.14 \pm 21.54^{*}$ & $0.22^{\dagger}$ \\
\hline
\end{tabular}

${ }^{\star}$ Data is reported in mean $\pm \mathrm{SD} ;{ }^{\dagger}$ Student's $t$-test; The differences between groups were analyzed using $\chi^{2}$-test; $\mathrm{PGF}_{2 \mathrm{a}^{\prime}}$ prostaglandin $\mathrm{F}_{2 \mathrm{a}^{\prime}}$; VC, vitamin C 


\section{Discussion}

Patient with persistent asthma is the target population in our study because of their high oxidative stress. ICSs have been used as standard treatment of persistent asthma, which is recommended by GINA. ${ }^{9}$ ICSs reduce airway inflammation by inhibition of cytokines and adhesion molecules gene expression. ${ }^{14}$ In our study, most participants had low levels of FENO, which was most likely a result of using daily ICS. Similarly, Montuschi et al. demonstrated that asthmatic patients receiving ICS revealed significantly lower FENO level than those without ICS. ${ }^{15}$ However, the direct effect of ICS on oxidative stress in asthma has been less extensively studied. It is probable that controlling inflammation of asthma with ICSs does not necessarily always control oxidative stress. Alzoghaibi et al. showed that the serum TBARS level in persistent asthmatic patients using ICSs for 3 months was still significantly higher than the healthy controls. ${ }^{16}$ Ozaras et al. demonstrated that the serum MDA levels of asthmatic patients treated with inhaled fluticasone $500 \mu \mathrm{g} /$ day for 1 month was significantly higher than the healthy controls. ${ }^{17}$ Thus, in patients with persistent asthma, the use of ICS decreases airway inflammation but might not dampen oxidative stress to the level of healthy controls.

The majority of asthmatic patients in our study had high plasma $\mathrm{PGF}_{2 a}$ concentration, indicating an increase in oxidative stress in these patients. This finding is in concordance with the results of previous studies ${ }^{16,17}$ as mentioned above. It is possible that exogenous oxidants such as cigarette smoke, airborne pollutants, and particulate matter may contribute to increase oxidative stress.

Although we predicted an association between eosinophilic airway inflammation and plasma PGF $_{2 \alpha}$ concentrations, we did not find any association.

The findings in our study were consistent with the results from the study by Montuschi et al. ${ }^{15}$ Although they found a positive correlation between the concentrations of $\mathrm{PGF}_{2 \alpha}$ in an $\mathrm{EBC}$ and the levels of FENO in asthmatic patients not taking ICSs, there was no correlation between the concentrations of $\mathrm{PGF}_{2 \alpha}$ in EBC and the levels of FENO in those taking ICSs. Similarly, Louhelainen et al. reported no significant correlation between sputum PGF $_{2 \alpha}$ and FENO levels in asthmatic patients. ${ }^{18}$ There is a possibility that FENO levels reflect different aspects of airway inflammation and are affected by many factors; ${ }^{19}$ thus, $\mathrm{PGF}_{2 \alpha}$ and FENO levels could increase independently of each other.

We also found that participants with severe asthma tended to have higher plasma $\mathrm{PGF}_{2 \alpha}$ concentrations than those with mild or moderate asthma; however, the difference was not significant. To our knowledge, this is the first study to show the relationship between plasma $\mathrm{PGF}_{2 \alpha}$ and asthma severity according to revised GINA criteria.

According to the available data, the prevalence of $\mathrm{Zn}$ deficiency in Thai school children in the northeastern and southern parts of Thailand was 57 and $31 \%$, respectively. ${ }^{20}$ In the present study, all participants had $\mathrm{Zn}$ deficiency. This finding was not due to low $\mathrm{Zn}$ intake since all participants had adequate $\mathrm{Zn}$ intake. There are several factors contributing to $\mathrm{Zn}$ deficiency in asthmatic patients such as high $\mathrm{Zn}$ utilization, redistribution, and increased excretion.
Zn has an antioxidant capacity; therefore, high oxidative stress in asthmatic patients may reduce the body $\mathrm{Zn}$ levels. In addition, asthma is a chronic inflammatory disease. The redistribution of plasma $\mathrm{Zn}$ to the cellular compartment can occur during excessive inflammation. ${ }^{21}$ Moreover, $\mathrm{Zn}$ is necessary for activation and recruitment of T-cell lymphocytes, mast cells, and eosinophils. ${ }^{22}$ Consequently, greater $\mathrm{Zn}$ demand by the immune system can be a contributing factor to $\mathrm{Zn}$ deficiency during the inflammatory stage. Because respiratory epithelial cells are rich in $\mathrm{Zn}$, the loss of respiratory epithelial tissues through shedding into airways during acute episodic attacks can deplete $\mathrm{Zn}$ reserves. ${ }^{23}$ It is possible that corticosteroid for treatment of asthma can affect the $\mathrm{Zn}$ status. Kakarash et al. reported that asthmatic children using steroid had lower serum $\mathrm{Zn}$ concentrations than those not using it. ${ }^{24}$ One of the proposed mechanisms for $\mathrm{Zn}$ deficiency caused by steroids is higher urinary $\mathrm{Zn}$ excretion in patients using corticosteroids. ${ }^{25}$

Although all participants in this study had $\mathrm{Zn}$ deficiency, there was no association between plasma $\mathrm{Zn}$ concentrations and asthma severity and asthma control. The results of our study are consistent with those reported by Bilan et al., investigating $\mathrm{Zn}$ status in asthmatic children. ${ }^{26}$ They reported no significant difference in plasma $\mathrm{Zn}$ levels between patients with intermittent asthma and those with persistent asthma. Bishopp et al. also reported no significant difference in the mean serum $\mathrm{Zn}$ concentrations between the severe and mild asthma groups. ${ }^{27}$ These findings suggest that asthma can contribute to $\mathrm{Zn}$ deficiency, but $\mathrm{Zn}$ status does not affect the severity of asthma or levels of asthma control in asthmatic patients.

In our study, a positive correlation between plasma $\mathrm{Zn}$ concentrations and $\mathrm{FEV}_{1}$ values as well as the $\mathrm{FEV}_{1} / \mathrm{FVC}$ ratio was found. Similarly, Jayaram et al. reported that the median of $\mathrm{Zn}$ concentrations in sputum was significantly lower in asthmatic participants with abnormal $\mathrm{FEV}_{1}$ than in those with normal $\mathrm{FEV}_{1}{ }^{28}$ Ghaffari et al. showed that $\mathrm{Zn}$ supplementation at the dose of $50 \mathrm{mg} /$ day for 8 weeks significantly increased both $\mathrm{FEV}_{1}$ levels and the $\mathrm{FEV}_{1} / \mathrm{FVC}$ ratio in asthmatic children than baseline. ${ }^{29}$ Accordingly, asthmatic patients with $\mathrm{Zn}$ deficiency, especially in those who have abnormal pulmonary function, should take $\mathrm{Zn}$ supplementation to help improve their pulmonary function.

The prevalence of VC deficiency in 50 Thai healthy adults (non-smokers and non-drinkers) and in 50 Thai smokers in 2018 was 8 and $22 \%$, respectively. ${ }^{30}$ So far, there was no report on the prevalence of VC deficiency in Thai children. Nearly $40 \%$ of participants in the present study had VC deficiency despite the fact that the median intake of VC in our study was high, supporting an increase in the utilization of VC to combat oxidative stress occurring in asthmatic patients. There is evidence showing that VC supplementation could reduce the levels of FENO in 16 hyperpnea-induced bronchoconstriction asthmatic patients. ${ }^{31}$ The results from our study demonstrated a lower mean plasma concentration of VC in participants with eosinophilic airway inflammation than that in those without inflammation. This may confirm an increase in the utilization of VC to alleviate airway inflammation in asthma. 
We found a significantly higher number of participants with severe asthma in the VC deficiency group than that in the normal VC group. There was a higher number of participants with incomplete asthma control in the VC deficiency group than that in the other group without a statistical significance. We also found that the VC deficiency group had a trend of having a higher mean plasma PGF $_{2 \alpha}$ concentration than the other group. This evidence may suggest the effect of high oxidative stress in severe asthma on the risk of VC deficiency in asthmatic patients. Our results are concordant with the results from the study of Harik-Khan et al. and Misso et al, showing that low plasma VC was independently associated with severe asthma. ${ }^{32,33}$

In our study, nearly $70 \%$ of participants had an airway obstruction $\left(\mathrm{FEV}_{1} / \mathrm{FVC} \leq 90 \%\right)$. The decline in the $\mathrm{FEV}_{1} / \mathrm{FVC}$ ratio corresponding to $\mathrm{VC}$ deficiency was observed in asthmatic participants. Apparently, VC deficiency not only affects the redox equilibrium, but also promotes eosinophilic airway inflammation, leading to the decline in pulmonary function.

All participants in our study had normal plasma VE concentrations, although nearly $90 \%$ of them reported low VE intakes. The report of low VE intake can be explained by insufficient data of VE contents in Thai food items. Since there was no VE deficiency found in the present study, the correlation among VE concentrations, asthma severity, and asthma control could not be demonstrated.

No statistically significant correlation was found between VE concentrations and pulmonary function in the present study. Ghaffari et al. reported a significantly inverse association between plasma VE concentrations and $\mathrm{FEV}_{1}$ levels and the $\mathrm{FEV}_{1} / \mathrm{FVC}$ ratio in children with moderate asthma. They found that the mean plasma VE concentration, FEV level, and the $\mathrm{FEV}_{1} / \mathrm{FVC}$ ratio were low. ${ }^{34} \mathrm{On}$ the other hand, Yamasaki et al. did not find an association between serum VE concentration and $\mathrm{FEV}$ levels as well as the $\mathrm{FEV}_{1} / \mathrm{FVC}$ ratio. ${ }^{35}$ In the study by Yamasaki et al., the mean serum VE concentration, $\mathrm{FEV}_{1}$ level, and the $\mathrm{FEV}_{1} / \mathrm{FVC}$ ratio were quite similar to those observed in the present study. The discrepancy between the studies may be due to the difference in status of VE and pulmonary function of participants. In our study, none of participants had VE deficiency. In addition, pulmonary function levels in our study were higher than those in the studies mentioned above.

The present study has several limitations. Firstly, this was a cross-sectional study that was conducted at a one-time point; therefore, we are unable to make a causal inference. Secondly, we did not have the data on the oxidative stress status and the status of $\mathrm{Zn}, \mathrm{VC}$, and $\mathrm{VE}$ in children without asthma at similar age group to compare with those with asthma. Despite not having a control group, $\mathrm{Zn}$ and VC deficiencies as well as the correlation between antioxidant nutrients and pulmonary function were demonstrated in the present study. Thirdly, the small sample size may limit the chances of achieving statistical significance in the results. Fourthly, although the assessment of micronutrient intakes, using the semi-quantitative FFQ and a qualified software, provides adequate information on long-term intakes, recall bias is possible resulting in over- or under-estimate of each nutrient intake.
And lastly, the assessment of VE intake was problematic because accurate data on food contents is limited.

\section{Conclusion}

Our study demonstrated that all asthmatic children had Zn deficiency. In addition, nearly $40 \%$ of them had VC deficiency. Reduction of $\mathrm{Zn}$ was associated with abnormal pulmonary function. The reduction of VC was associated with severe asthma, airway obstruction, and eosinophilic airway inflammation. Therefore, assessment of plasma $\mathrm{Zn}$ and VC status as well as nutritional status should be included in asthma management. For those who have deficiencies of $\mathrm{Zn}$ and/ or VC, supplementations of these nutrients together with nutritional counseling should be provided to ameliorate asthma management.

\section{Acknowledgments}

We are grateful to Ms. Umaporn Udomsubpayakul for her help in sample size calculation. Our grateful thanks are extended to Ms. Purisa Wecharak and Ms. Phanphen Phoonlapdacha for their assistance with collection of blood samples and dietary intakes, to Mrs. Wanlapa Jotikasthira and Mrs. Cherapat Sasisakulporn for doing pulmonary function tests and exhaled nitric oxide measurements, and to Mrs. Belen Feungpean and Mrs. Areeporn Sangcakul for blood sample analysis. We express our gratitude to participants and their parents for their participation.

\section{Authors disclosure}

None of the authors reported a conflict of interest related to the study. This study was funded by Ramathibodi Research Grant, Faculty of Medicine Ramathibodi Hospital, Mahidol University, Thailand.

\section{Author contributions}

- Siriporn Siripornpanich: Setting the study design, performing data collection, data analysis and interpretation, and writing the manuscript

- Nalinee Chongviriyaphan: Initiating the research question, setting the study design, supervision of data collection, data analysis and interpretation, writing and editing the manuscript, and approval of the final manuscript

- Wiparat Manuyakorn: Contributing to the study design, editing the manuscript, supervision of data collection and interpretation, and approval of the final manuscript.

- Ponpan Matangkasombut: Contributing to the study design, editing the manuscript, and approval of the final manuscript.

\section{References}

1. Asher MI, Montfort S, Björkstén B, Lai CK, Strachan DP, Weiland SK, et al. Worldwide time trends in the prevalence of symptoms of asthma, allergic rhinoconjunctivitis, and eczema in childhood: ISAAC phase one and three repeat multicountry cross-sectional surveys. Lancet. 2006;368(9537):733-43.

2. Boldogh I, Bacsi A, Choudhury BK, Dharajiya N, Alam R, Hazra TK, et al. ROS generated by pollen NADPH oxidase provide a signal that augments antigen-induced allergic airway inflammation. J Clin Invest. 2005;115(8):2169-79. 
3. Shalaby KH, Allard-Coutu A, O'Sullivan M, Qureshi ST, Day BJ, Martin JG. Inhaled birch pollen extract induces airway hyperresponsiveness via oxidative stress but independently of pollen-intrinsic NADPH oxidase activity, or the Toll-like receptor 4-TRIF pathway. J Immunol. 2013;191(2):922-33.

4. Voynow JA, Kummarapurugu A. Isoprostanes and asthma. Biochimica et Biophysica Acta. 2011;1810:1091-5.

5. Basu S. Bioactive eicosanoids: Role of prostaglandin F(2alpha) and $\mathrm{F}(2)$-isoprostanes in inflammation and oxidative stress related pathology. Mol Cell Biol. 2010;30(5):383-91.

6. Kalayci O, Besler T, Kilinç K, Several BE, Saraçlar Y. Serum levels of antioxidant vitamins (alpha tocopherol, beta carotene, and ascorbic acid) in children with bronchial asthma. Turk J Pediatr. 2000;42(1):17-21.

7. Vural H, Uzun K, Uz E, Koçyigit A, Cigli A, Akyol O. Concentrations of copper, zinc and various elements in serum of patients with bronchial asthma. J Trace Elem Med Biol. 2000;14(2):88-91.

8. Al-Afaleg NO, Al-Senaidy A, El-Ansary A. Oxidative stress and antioxidant status in Saudi asthmatic patients. Clin Biochem. 2011;44 (8-9):612-7.

9. Global Initiative for Asthma (GINA) Executive and Science committees. Global strategy for asthma management and prevention updated 2015 [Internet]. Global Initiative for Asthma (GINA); 2016 [cited 2017 Sep 19]. Available from: http://ginasthma.org/wp-content/uploads/2016/01/ GINA_Report_2015_Aug11-1.pdf.

10. Pellegrino R, Viegi G, Brusasco V, Crapo RO, Burgos F, Casaburi $\mathrm{R}$, et al. Interpretative strategies for lung function tests. Eur Respir J. 2005;26(5):948-68.

11. Dweik RA, Boggs PB, Erzurum SC, Irvin CG, Leigh MW, Lundberg JO, et al. An official ATS clinical practice guideline: interpretation of exhaled nitric oxide levels (FENO) for clinical applications. Am J Respir Crit Care Med. 2011;184(5):602-15

12. Al-Abdulla NO, Al Naama M, Hassan MK. Antioxidant status in acute asthmatic attack in children. J Pak Med Assoc. 2010;60(12):1023-7.

13. Ross AC, Caballero B, Cousins RJ, Turner KL, Ziegler TR. Modern nutrition in health and disease. 11th ed. Philadelphia: Lippincott Williams \& Wilkins; 2013.

14. Barnes PJ. Inhaled Corticosteroids. Pharmaceuticals. 2010;3:514-40.

15. Montuschi P, Corradi M, Ciabattonu G, Nightingale J, Kharitonov SA, Barnes PJ. Increased 8-Isoprostane, a marker of oxidative stress, in exhaled condensate of asthma patients. Am J Respir Crit Care Med. 1999;160(1):216-20.

16. Alzoghaibi MA, Bahammam AS. Lipid peroxides in stable asthmatics receiving inhaled steroids and long-acting b2-agonists. Respirology. 2007;12:439-42

17. Ozaras R, Tahan V, Turkmen S, Talay F, Besirli K, Aydin S, et al. Changes in malondialdehyde levels in bronchoalveolar fluid and serum by the treatment of asthma with inhaled steroid and beta2-agonist. Respirology 2000;5(3):289-92.

18. Louhelainen N, Rytilä $\mathrm{P}$, Obase $\mathrm{Y}$, Mäkelä $\mathrm{M}$, Haahtela $\mathrm{T}$, Kinnula VL, et al. The value of sputum 8 -isoprostane in detecting oxidative stress in mild asthma. J Asthma. 2008;45(2):149-54.

19. Banovcin P, Jesenak M, Michnova Z, Babusikova E, Nosal S, Mikler J, et al. Factors attributable to the level of exhaled nitric oxide in asthmatic children. Eur J Med Res. 2009;14 Suppl 4:S9-13.
20. Pinkaew S, Winichagoon P, Hurrell RF, Wegmuller R. Extruded rice grains fortified with zinc, iron, and vitamin A increase zinc status of Tha school children when incorporated into a school lunch program. J Nutr. 2013;143(3):362-8.

21. Liuzzi JP, Lichten LA, Rivera S, Blanchard RK, Aydemir TB, Mitchell $\mathrm{D}$, et al. Interleukin-6 regulates the zinc transporter Zip14 in liver and contributes to the hypozincemia of the acute-phase response. Proc Natl Acad Sci USA. 2005;102(19):6843-8.

22. Hönscheid A, Rink L, Haase H. T-lymphocytes: a target for stimulatory and inhibitory effects of zinc ions. Endocr Metab Immune Disord Drug Targets. 2009;9(2):132-44.

23. Murgia C, Grosser D, Truong-Tran AQ, Roscioli E, Michalczyk A, Ackland ML, et al. Apical localization of zinc transporter ZnT4 in human airway epithelial cells and its loss in a murine model of allergic airway inflammation. Nutrients. 2011;3(11):910-28.

24. Kakarash TA, Al-Rabaty A. Zinc status in children with bronchial asthma. Iraqi Postgrad Med J. 2012;11:698-703.

25. Peretz A, Neve J, Famaey JP. Effects of chronic and acute corticosteroid therapy on zinc and copper status in rheumatoid arthritis patients. J Trace Elem Electrolytes Health Dis. 1989;3(2):103-8.

26. Bilan N, Barzegar M, Pirzadeh H, Saboktakin L, Haghjo AG. Serum copper and zinc levels of children with asthma. Int J Curr Res Aca Rev. 2014;2(8):266-73.

27. Bishopp A, Sathyamurthy R, Manney S, Webbster C, Krishna MT, Mansur AH. Biomarkers of oxidative stress and antioxidants in severe asthma: A Prospective Case-Control Study. Ann Allergy Asthma Immunol. 2017;118(4):445-51.

28. Jayaram L, Chunilal S, Pickering S, Ruffin RE, Zalewski PD. Sputum zinc concentration and clinical outcome in older asthmatics. Respirology. 2011;16(3):459-66

29. Ghaffari J, Khalilian A, Salehifar E, Khorasani E, Rezaii MS. Effect of zinc supplementation in children with asthma: a randomized, placebo -controlled trial in northern Islamic Republic of Iran. East Mediterr Health J. 2014;20(6):391-6.

30. Boonpangrak S, Tantimongcolwat T, Treeratanapiboon L, Leelahakul P, Prachayasittikul V. Lifestyle behaviors and serum vitamin $\mathrm{C}$ in the Thai population in Bangkok Metropolitan. EXCLI J. 2018;17:452-66.

31. Mickleborough TD, Lindley MR. The effect of combining fish oil and vitamin $\mathrm{C}$ on airway inflammation and hyperpnea-induced bronchoconstriction in asthma. J Allergy Ther [Internet]. 2014 [cited 2017 Oct 17];5:184. Available from: https:/www.omicsonline.org/open -access/the-effect-of-combining-fish-oil-and-vitamin-c-on-airway-inflam mation-2155-6121.1000184.pdf.

32. Harik-Khan RI, Muller DC, Wise RA. Serum vitamin levels and the risk of asthma in children. Am J Epidemiol. 2004;15(4):351-7.

33. Misso NL, Brooks-Wildhaber J, Ray S, Vally H, Thompson PJ. Plasma concentrations of dietary and nondietary antioxidants are low in severe asthma. Eur Respir J. 2005;26(2):257-64.

34. Ghaffari J, Farid-Hossiani R, Khalilian A, Nahanmoghadam N, Salehifar E, Rafatpanah H. Vitamin e supplementation, lung functions and clinical manifestations in children with moderate asthma. Iran J Allergy Asthma Immunol. 2014;13(2):98-103.

35. Yamasaki A, Kawasaki Y, Takeda K, Harada T, Hasegawa Y, Fukushima T, et al. Relationship between oxidative stress, physical activity, and vitamin intake in patients with asthma. Yonago Acta Med. 2017;60:86-93. 